\title{
Disability in leprosy: a relevant measurement of progress in leprosy control
}

\author{
WCS SMITH, US ANTIN, AR PATOLE \\ Belgaum Leprosy Hospital, The Leprosy Mission, Belgaum \\ 591108, Karnataka State, India
}

Received for publication 1 December 1979.

Summary 931 patients have been detected in a Leprosy Control Project in Karnataka, India, giving a prevalence of 4.86/1000. 292 of these cases have disability and these are analysed in detail using the WHO Disability Index DI - 2. The effects of different forms of treatment on this Index are examined. It is suggested that incidence of disability is a more relevant measurement of the effectiveness of leprosy work than the incidence of cases. Secondary preventative measures are unlikely to prevent new cases whereas primary preventative measures for disability should affect the incidence of disability. This study forms the base line of a prospective study of the incidence of disability.

\section{Introduction}

It is well recognized that leprosy control is unlikely to be achieved using the current methods of secondary prevention (Meade, 1971). ${ }^{1}$ The well-documented fact in some countries that quality of leprosy control has little effect on the number of new cases occuring (Davey, 1974) ${ }^{2}$ after an initial fall, tends to have a depressing effect on field workers in leprosy control. In the light of these reports they feel they have been given an almost impossible task.

The vast amount of literature now appearing in journals and the press regarding a vaccine for leprosy increases this depression. Why should we struggle with very difficult work when an easier method is shortly to be produced? The fact that a vaccine will not shortly be available (Godal, 1978) ${ }^{3}$ is not always pointed out clearly.

It is deformity which sets leprosy apart from other diseases (Brand, 1964) ${ }^{4}$ and to the lay person leprosy means deformity (Scrinivasan and Dharmendra, 1978). ${ }^{5}$ This is something we should use as a more relevant measurement of leprosy work until the day of primary prevention dawns. Our concern should be the occurrence of deformity rather than the occurrence of cases since leprosy is in a very real sense deformity. 
Information about the epidermiology of disability in leprosy is increasing (Chum et al., 1970; ${ }^{6}$ Cross, $1972^{7}$ Karat et al., 1970, ${ }^{8} 1972 ; ;^{8} 1975 ;{ }^{9}$ Hansan, 1977; ${ }^{10}$ Bravo and Ratard, 1977). ${ }^{11}$ The various studies have used different criteria for evaluating disability. The proposed disability index (Bechelli and Domingue, ${ }^{2}$ 1971) $)^{12}$ gives a method of evaluation for use in comparisons between different areas and from time to time. Most of these studies are prevalance studies although some give development and progress in treatment of disability.

This study sets out as a baseline to examine the prevalence of disability and the various factors effecting this and the general background details of leprosy in the area. Yearly assessments are planned to look at the incidence of disability as a more relevant criteria of the efficiency of leprosy work.

\section{Methods}

Survey of the general population was carried out in two Talukas (Rural) of Belgaum District, Karnataka in India, according to the guidelines for Leprosy Control Programme in India, in a target population of 233,581 (1971 census) located in 126 villages ranging from 75 to 18,950 population.

The programme was carried out by health education at individual, panchayat and village levels; survey by house to house examinations, school survey and household contact surveillance. The work was carried out over a 3-year period, 1976-79, by a team of 11 paramedical workers, one nonmedical supervisor (NMS) and one medical officer. All trained in leprosy.

All cases detected were confirmed by the NMS or Medical Officer at the nearest clinic and at the same time disability assessment was performed by the physiotherapy technician in the form of Disability Index - (DI - 2) (Bechelli, et al. 1971). ${ }^{12}$

All patients were commenced on Dapsone therapy given at monthly intervals at 31 clinics.

For analysis of the various groups the standard measurements of percentage disabled and the the mean DI -2 of the disabled patients have been used.

\section{Results}

\section{ANALYSIS OF ALL DETECTED CASES}

The population enumerated in house to house survey showed a $2.7 \%$ increase in the 1971 census figure ( $37.8 \%$ of the population was 14 years and under).

The gross percentage examination of the enumerated population was $80 \%$ and the variation with age and sex is recorded in Table 1 . Since the population was not uniformly examined the 931 detected cases represent $75 \%$ and not 
Table 1. Percentage of examination by age and sex

\begin{tabular}{cccccc}
\hline Age and sex groups & Male & Female & Male child & Female child & Total \\
\hline Examination & 67 & 82 & 88 & 90 & 80 \\
\hline
\end{tabular}

$80 \%$ of estimated cases because the group of highest prevalence (male adults) had the lowest examination rate. Since $28 \%$ of cases presented voluntarily, clearly more than $75 \%$ of total cases have been detected.

It is important to consider the distribution of all cases by age, sex type, means of detection and the various prevalence rates before analysing the disabilities. These details are recorded in Table 2. The gross prevalence rate was found to be 4.86 per thousand and the male adult, female adult and child prevalence rates were $8.89,4.34$ and 2.59 per 1000 respectively.

Table 2 shows that at the lepromatous end of the spectrum there is an increase in the percentage of adult males and voluntary cases which all have an important influence in the distribution of disability.

\section{DISABILITIES AND SEX}

The details of disabilities and sex are recorded in Tables 2, 3, 4 and 5. The percentage of female patients with disability (20\%) is significantly less than that of male patients $(38 \%)(\mathrm{p}<0.05)$. The mean DI for female patients is less than for male patients but the difference is not significant. The difference in the percentage disabled can be accounted for by the fact that the Borderline Lepromatous (BL) and Leprosmatous (LL) case have the greatest numbers of disabled patients and also the highest male/female ratio. Both sexes show rise in disability with age and the mean age of disabled patients is the same in both sexes.

Table 2. Analysis of detected cases by age, sex and type showing mean age and main methods of detection

\begin{tabular}{lcccccc}
\hline & I & T & BT & BL & LL & Total \\
\hline Male adult & 45 & 174 & 96 & 38 & 118 & 471 \\
Male child & 55 & 52 & 11 & - & 2 & 120 \\
Female adult & 34 & 131 & 58 & 12 & 18 & 253 \\
Female child & 38 & 34 & 13 & 1 & 1 & 87 \\
Total & 172 & 391 & 178 & 51 & 139 & 931 \\
Mean age in years & 19.8 & 32.2 & 37.0 & 43.5 & 39.4 & 32.2 \\
By general \% & & & & & & \\
house to house & 84 & 73 & 66 & 61 & 36 & 68 \\
Voluntary \% & 6 & 21 & 31 & 39 & 63 & 28 \\
Other & 10 & 6 & 3 & - & 1 & 4 \\
Prevalence & & & & & & \\
rates/1000 & 0.90 & 2.04 & 0.93 & 0.27 & 0.73 & 4.86 \\
Sex ratio M/F & 1.4 & 1.4 & 1.5 & 2.9 & 6.3 & 1.7 \\
\hline
\end{tabular}


Table 3. Disabilities by sex and type

\begin{tabular}{|c|c|c|c|c|c|c|c|c|c|c|c|c|}
\hline \multicolumn{6}{|c|}{ Males } & \multicolumn{3}{|c|}{ Females } & \multicolumn{3}{|c|}{ Total } & \multirow[b]{2}{*}{$\begin{array}{c}\text { Mean } \\
\text { DI }\end{array}$} \\
\hline & $\begin{array}{l}\text { No of } \\
\text { cases }\end{array}$ & $\begin{array}{c}\text { No dis- } \\
\text { abled } \\
\end{array}$ & $\begin{array}{c}\% \text { dis- } \\
\text { abled }\end{array}$ & $\begin{array}{c}\text { Mean } \\
\text { DI } \\
\end{array}$ & $\begin{array}{l}\text { No of } \\
\text { cases }\end{array}$ & $\begin{array}{c}\text { No dis- } \\
\text { abled } \\
\end{array}$ & $\begin{array}{c}\% \text { dis- } \\
\text { abled }\end{array}$ & $\begin{array}{c}\text { Mean } \\
\text { DI } \\
\end{array}$ & $\begin{array}{c}\text { No of } \\
\text { cases }\end{array}$ & $\begin{array}{c}\text { No dis- } \\
\text { abled } \\
\end{array}$ & $\begin{array}{c}\% \text { dis- } \\
\text { abled }\end{array}$ & \\
\hline I & 100 & 0 & 0 & 0 & 72 & & & - & 172 & - & - & - \\
\hline $\mathrm{T}$ & 226 & 48 & 21 & 0.8 & 165 & 21 & 13 & 0.9 & 391 & 69 & 18 & 0.8 \\
\hline BT & 107 & 62 & 58 & 1.3 & 71 & 29 & 41 & 1.0 & 178 & 91 & 51 & 1.2 \\
\hline $\mathrm{BL}$ & 38 & 27 & 71 & 1.2 & 13 & 10 & 77 & 1.4 & 51 & 37 & 73 & 1.3 \\
\hline LL & 120 & 86 & 72 & 1.2 & 19 & 9 & 47 & 1.0 & 139 & 95 & 68 & 1.2 \\
\hline Total & 591 & 223 & 38 & 1.2 & 340 & 69 & 20 & 1.0 & 931 & 292 & 31 & 1.1 \\
\hline
\end{tabular}




\section{DISABILITIES AND TYPE}

Details of disabilities and type of leprosy is recorded in Tables 2, 3 and 5. The percentage of disabled cases varies with type, the highest being the BL and LL groups. The mean DI is least in the tuberculoid (TT) group. There is also a rise in the mean age of the groups from TT and LL. Type of leprosy is clearly a major factor in disability. The BL group has the highest percentage disabled and the highest mean DI.

\section{DISABILITIES AND AGE}

Details of disabilities and age are recorded in Tables 2, 4, 5 and Graphs 1 and 2. The mean age for all patients is 32.2 years and for the disabled patients it is 43.0 years. The average age increases towards lepromatous end with BL cases having the highest mean age. The percentage of disabled patients increases with age as seen in Table 4 as also does the mean DI. Graph 1 is of the mean DI against age.

Mean

DI-2

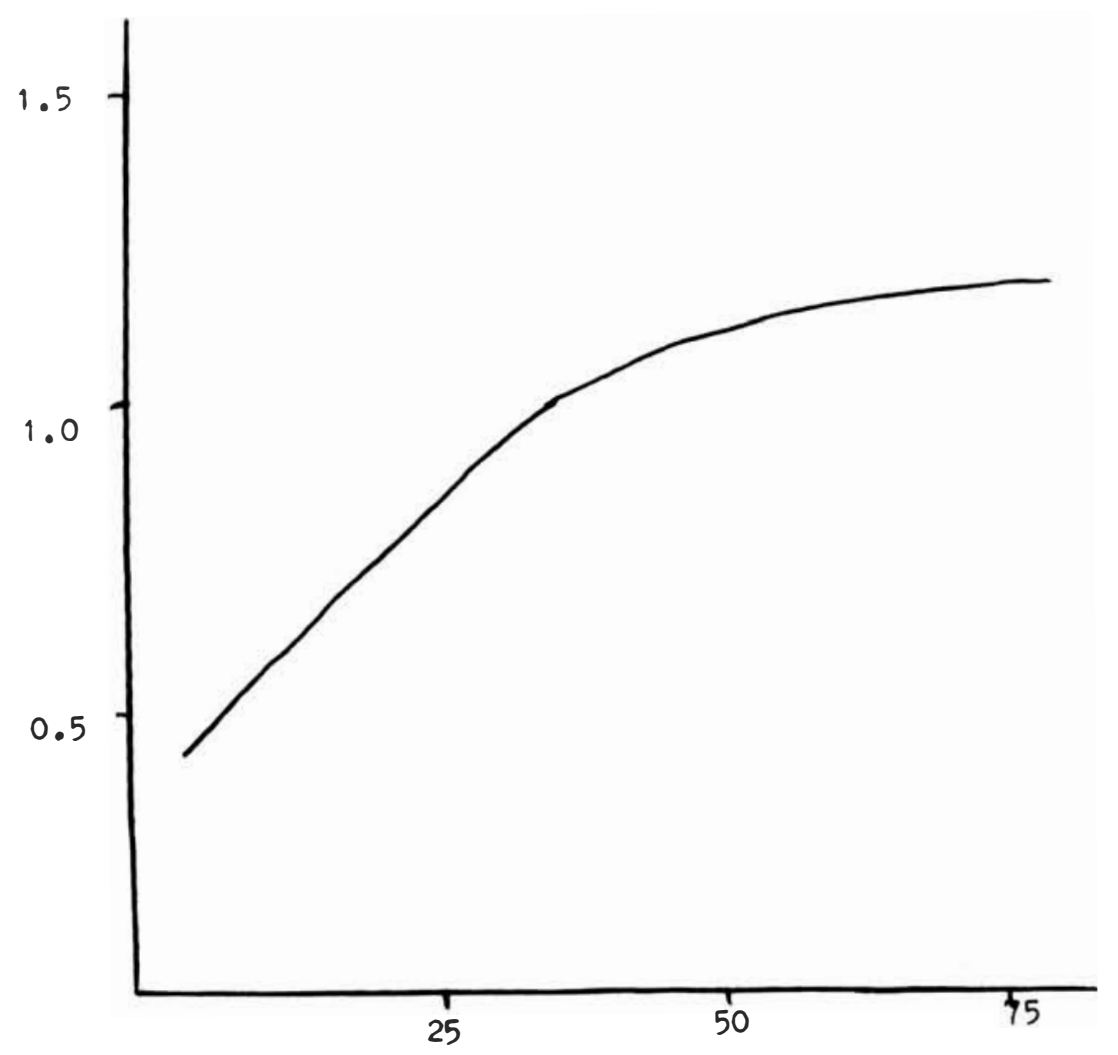

Age in Years

Graph 1. Mean disability index -2 against age 
Table 4. Disabilities by sex and type

\begin{tabular}{|c|c|c|c|c|c|c|c|c|c|c|c|c|}
\hline & \multicolumn{4}{|c|}{ Males } & \multicolumn{4}{|c|}{ Females } & \multicolumn{3}{|c|}{ Total } & \multirow[b]{2}{*}{$\begin{array}{c}\text { Mean } \\
\text { DI }\end{array}$} \\
\hline & $\begin{array}{l}\text { No of } \\
\text { cases }\end{array}$ & $\begin{array}{l}\text { No dis- } \\
\text { abled }\end{array}$ & $\begin{array}{l}\% \text { dis- } \\
\text { abled }\end{array}$ & $\begin{array}{c}\text { Mean } \\
\text { DI }\end{array}$ & $\begin{array}{l}\text { No of } \\
\text { cases }\end{array}$ & $\begin{array}{l}\text { No dis- } \\
\text { abled }\end{array}$ & $\begin{array}{l}\% \text { dis- } \\
\text { abled }\end{array}$ & $\begin{array}{c}\text { Mean } \\
\text { DI }\end{array}$ & $\begin{array}{l}\text { No of } \\
\text { cases }\end{array}$ & $\begin{array}{l}\text { No dis- } \\
\text { abled }\end{array}$ & $\begin{array}{l}\% \text { dis- } \\
\text { abled }\end{array}$ & \\
\hline $0-4$ & 3 & - & - & - & 6 & 1 & 17 & 0.5 & 9 & 1 & 11 & 0.5 \\
\hline $5-14$ & 117 & 5 & 4 & 0.4 & 81 & 4 & 5 & 0.5 & 198 & 0 & 5 & 0.4 \\
\hline $15-24$ & 88 & 18 & 20 & 0.7 & 41 & 6 & 15 & 1.3 & 129 & 24 & 19 & 0.8 \\
\hline $25-34$ & 93 & 32 & 34 & 1.1 & 53 & 8 & 15 & 0.9 & 146 & 40 & 27 & 1.0 \\
\hline $35-44$ & 109 & 62 & 57 & 1.3 & 58 & 13 & 22 & 1.1 & 167 & 75 & 45 & 1.3 \\
\hline $45-54$ & 115 & 64 & 56 & 1.2 & 52 & 19 & 37 & 1.0 & $167^{\circ}$ & 83 & 50 & 1.2 \\
\hline $55-64$ & 40 & 32 & 64 & 1.3 & 37 & 14 & 38 & 1.3 & 87 & 46 & 53 & 1.3 \\
\hline $65+$ & 16 & 10 & 63 & 1.2 & 12 & 4 & 33 & 1.2 & 28 & 14 & 50 & 1.1 \\
\hline Total & 591 & 223 & 38 & 1.2 & 340 & 69 & 20 & 1.0 & 931 & 292 & 31 & 1.1 \\
\hline
\end{tabular}




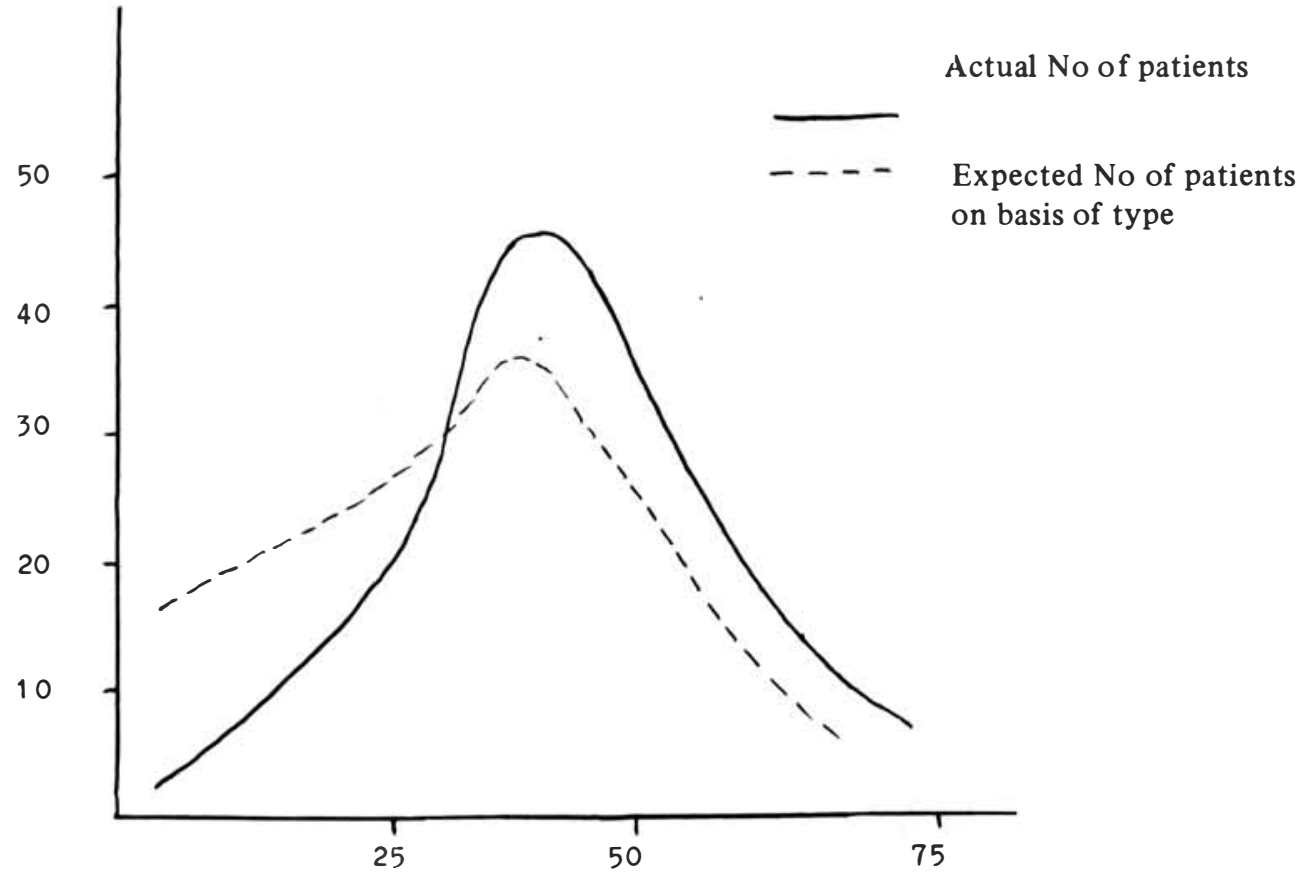

The actual number of patients lags behind the expected number of disabled patients standardized on the basis of type, showing that age affects disability independently from type of leprosy.

Graph 2. Number of disabled patients against age

Since the older age groups have less Indeterminate (I) and TT cases and more borderline and lepromatous, on the basis of classification alone an increase in disability with age would be expected. In Graph 2 each age group has been standardized for type of leprosy and the expected cases for each age group plotted. On the same graph the actual figures have been plotted and it is seen that age has an effect on disability apart from type.

Table 5. Mean age of disabled patients and of total patients by sex and type

\begin{tabular}{|c|c|c|c|c|c|c|}
\hline & \multicolumn{2}{|c|}{ Male } & \multicolumn{2}{|c|}{ Female } & \multicolumn{2}{|c|}{ Total } \\
\hline & Total & Disabled & Total & Disabled & Total & Disabled \\
\hline I & 18.7 & - & 21.4 & - & 19.8 & - \\
\hline $\mathrm{T}$ & 30.5 & 41.9 & 34.5 & 43.7 & 32.2 & 42.4 \\
\hline BT & 38.5 & 41.4 & 36.6 & 42.7 & 37.0 & 41.8 \\
\hline BL & 45.2 & 46.1 & 38.6 & 43.0 & 43.5 & 45.2 \\
\hline LL & 40.0 & 44.3 & 36.1 & 40.9 & 39.4 & 44.0 \\
\hline Total & 32.1 & 43.2 & 32.4 & 42.8 & 32.2 & 43.0 \\
\hline
\end{tabular}


The gap in the mean age of each classification group from the mean age of the disabled is largest for tuberculoid patients and very small for borderline and lepromatous.

\section{ACTUAL DISABILITIES}

The actual disabilities are recorded in Table 6. If it is accepted that anaestheasia and absorptions of hands and feet, stiff joints and blurring of vision are all irreversible then the revisible component amounts to $17.6 \%$ of the total disability.

The reversible components can be subdivided into those reversed by surgery such as mobile claw hand, claw toes, drop foot and lagophthalmos and those reversed by health education, MCR chappals and OPP Boots. Surgery accounts for $7.3 \%$ and health education to $10.3 \%$.

The cases which may benefit from surgery were analysed individually for suitability (Andersen, 1974). ${ }^{13}$ Out of all cases of foot drop and mobile claw hand only 16 were suitable, others being excluded because of positive smears, absorptions or age. Also claw toes not associated with foot drop were excluded. Out of the 16 patients, 6 have refused surgery because they are coping at their employment despite disability. Thus the realistic component reversible by surgery is only $1.2 \%$ of the total disability. Stiff joints may be reversed but these are not included.

The disability which can be corrected by health education includes injuries and ulcers of the hands and planter ulceration. Again $100 \%$ reversal is unrealistic

Table 6. Actual disabilities

\begin{tabular}{lcr}
\hline Anaesthesia only & $117(40 \%)$ & \\
Anaesthesia \& deformity & $175(60 \%)$ & \\
Total & $292(100 \%)$ & Bilateral \\
\hline & Total & \\
\hline Hands & & 5 \\
$\quad$ Ulcers and injuries & 16 & 9 \\
$\quad$ Mobile claw hand & 35 & 30 \\
Slight absorption & 53 & 13 \\
Stiff joints & 25 & 3 \\
Severe absorption & 9 & 20 \\
Feet & & 5 \\
Tropic ulcers & 60 & 2 \\
Claw toes & 12 & 31 \\
Foot drop & 13 & 2 \\
Slight absorption & 50 & 1 \\
Severe absorption & 7 & 1 \\
Face & & \\
$\quad$ Lagophthalmos & 2 & \\
Blurring vision & 2 & \\
\hline
\end{tabular}


Table 7. Relationship between disability and deformity (type wise)

\begin{tabular}{lccccc}
\hline & $\mathrm{T}$ & $\mathrm{BT}$ & $\mathrm{BL}$ & $\mathrm{LL}$ & Total \\
\hline Disabled & $69(18 \%)$ & $91(51 \%)$ & $37(73 \%)$ & $95(68 \%)$ & $292(31 \%)$ \\
$\begin{array}{l}\text { Deformity } \\
\text { Ratio }\end{array}$ & $42(11 \%)$ & $52(32 \%)$ & $23(45 \%)$ & $53(38 \%)$ & $175(19 \%)$ \\
$\quad$ Deformity/Disability & 0.61 & 0.57 & 0.62 & 0.56 & 0.60 \\
\hline
\end{tabular}

and a large series shows up to $40 \%$ recurrence of ulceration despite health education, POP and use of MCR chappals. (Sderberg, 1970). ${ }^{14}$ So that more realistically only $7.1 \%$ to total disability can be reversed by these methods.

Thus although $17.6 \%$ of all disability is potentially reversible, only $8.3 \%$ could be achieved realistically, if reconstructive surgery were available, health education, Physiotherapy, POP casts and MCR chappals.

\section{DISABILITY AND DEFORMITY}

The relationship between disability and deformity is recorded in Table 7. Sixty per cent of all disabled patients have deformity (altered shape) and this ratio does not vary with classification; being remarkedly constant.

\section{DISABILITY AND MODE OF CASE DETECTION}

The analysis of disability, mode of detection and type is set out in Table 8. Of those detected by house to house survey, $23 \%$ had disability whereas of those who reported voluntarily, $58 \%$ had disability. In the BL and LL groups, the percentage disabled did not vary with mode of detection whereas in the BT and TT there was marked variation.

\section{Discussion}

The leprosy disabilities in a leprosy control programme have been analysed using the WHO DI -2 Index. This shows that $31 \%$ have some disability and mean DI for those disabled is 1.1. It has been shown that many factors influence the prevalence of disability and these factors have been analysed. Less female patients were disabled than male but the greatest $\mathrm{M} / \mathrm{F}$ ratios are at the lepromatous end of the spectrum. Type of leprosy was a major factor in disability. Percentage disability and mean DI increased with age independently from type. Analysis of the actual disabilities showed that health education, etc, had a greater potential in reducing disability than reconstructive surgery.

The relationship between disability and deformity (altered shape) did not vary with type. Patients who presented voluntarily showed a much higher percentage of disabled than those found in house to house survey. 
Table 8. Disabilities and the mode of detection

\begin{tabular}{|c|c|c|c|c|c|c|c|c|c|c|}
\hline & \multicolumn{2}{|c|}{$\begin{array}{l}\text { House to house } \\
\text { survey }\end{array}$} & \multicolumn{2}{|c|}{$\begin{array}{l}\text { Voluntary } \\
\text { reporting }\end{array}$} & \multicolumn{2}{|c|}{ School survey } & \multicolumn{2}{|c|}{$\begin{array}{c}\text { Household } \\
\text { Contact survey }\end{array}$} & \multicolumn{2}{|c|}{ By all modes } \\
\hline & $\begin{array}{l}\text { No of } \\
\text { cases }\end{array}$ & $\begin{array}{l}\% \text { Dis- } \\
\text { abled }\end{array}$ & $\begin{array}{l}\text { No of } \\
\text { cases }\end{array}$ & $\begin{array}{c}\% \text { Dis- } \\
\text { abled }\end{array}$ & $\begin{array}{l}\text { No of } \\
\text { cases }\end{array}$ & $\begin{array}{l}\% \text { Dis- } \\
\text { abled }\end{array}$ & $\begin{array}{l}\text { No of } \\
\text { cases }\end{array}$ & $\begin{array}{l}\% \text { Dis- } \\
\text { abled }\end{array}$ & $\begin{array}{l}\text { No of } \\
\text { cases }\end{array}$ & $\begin{array}{c}\% \text { Dis- } \\
\text { abled }\end{array}$ \\
\hline I & 144 & - & 11 & - & 6 & - & 11 & - & 172 & - \\
\hline $\mathrm{T}$ & 287 & 13 & 81 & 46 & 10 & - & 13 & - & 391 & 18 \\
\hline BT & 118 & 40 & 56 & 73 & 3 & 33 & 1 & - & 178 & 51 \\
\hline BL & 31 & 74 & 20 & 70 & - & - & - & - & 51 & 73 \\
\hline LL & 50 & 76 & 88 & 65 & - & - & 1 & - & 139 & 68 \\
\hline Total & 630 & 23 & 256 & 58 & 19 & 5 & 26 & 0 & 931 & 31 \\
\hline
\end{tabular}


When analysing the rates of leprosy it is seen that the prevalence rate falls quite rapidly when a treatment programme is started mainly due to the reduction in duration of the disease, whereas the incidence rate is constant after an initial drop. This initial drop can be explained by low examination rates in the higher prevalence group, ie male adults which is gradually made up in subsequent survey; the keeping of suspects which on subsequent survey are identified as cases also produces this fall.

This study is the start of a prospective study looking at the prevalence and incidence rates of disability. Since it is disability which sets leprosy apart from other diseases and results in the major problems, disability rates may be a more important and relevant measure of the effectiveness. of a leprosy detection and treatment programme than the number of actual cases. Leprosy control by detection and treatment of cases, ie secondary prevention, cannot be a very effective method of control and leads to despondency among field workers. It should be noted that disease arrested is not synomymous with disability arrested.

Disability control on the other hand is a method of primary prevention. Since a high risk group can be selected, ie those who have leprosy but no disability and disability prevented by treatment, health education, etc. It is suggested that the prevalence rate of disability will fall slowly as severely disabled patients become old and die; and that the incidence rates of disability will fall more rapidly as cases are detected and treated early and deterioration is prevented in established cases.

We suggest that analysis of disability prevalence and incidence rates is more relevant measure of a leprosy programme's effectiveness until the day of primary disease prevention eventually dawns.

\section{Acknowledgements}

This work was carried out in the Leprosy Mission Hospital in Belgaum. We are grateful to the team of 11 paramedical workers and the physiotherapy technician for their work and to Mr P T Edward for preparing the manuscript.

\section{References}

1 Meade TW. Epidermiology and leprosy control. Lepr Rev, 1974, 42, 14.

2 Davey TF. Editorial - Realisim in leprosy control. Lepr Rev, 1974, 45, 197.

3 Godal T. The Clayton Memorial Lecture 1978: Is immunoprophylaxis in leprosy feasible? Lepr Rev, 1978, 49, 305.

4 Brand PW. Deformity in leprosy. In: Cochrane, Davey, eds. Leprosy in theory and practice. John Wright \& Sons, 1964, 2nd ed, 447.

5 Scrinivasan H, Dharmendra. Deformities in leprosy. Leprosy Volume 1. Dharmendra. Kothari Medical Publishing House, Chapter 27, page 197.

6 Chum HJ, Otsijula Y. Leprosy disability in Yimbo and its economica effects. East A frican Med J, 1970, 47, 389. 
7 Cross AB. Foot deformities in leprosy - A survey in the Solomon Islands. Lepr Rev, 1972, 43, 45.

8 Karat S, Rao PSS, Karat ABA. Prevalence of deformities and disabilities among leprosy patients in an endemic area. Int J Lepr, Part I, 1970, 38, 1, and Part II, 1972, 40, 265.

9 Karat S, Ranney DA, Kurian PV. Rehabilitation of leprosy patients. Final Report SRS IND 32-68, 1975.

10 Hasan S. A survey of leprosy deformities among the patients of Hyderabad City. Leprosy in India, 1977, 48, 393.

11 Bravo and Ratard ...... 1977

12 Bechelli LM and Dominguez VM. Disability Index for leprosy patients. Bull Wld Hlth Org, 1971, 44, 709,

13 Andersen JG. Indications and contra indications for reconstructive surgery. Lepr Rev, 1974, 45, 185.

14 Sderberg G. Followup of application of plaster-of-Paris casts for non-infected plantar ulcers in field conditions. Lepr Rev, 1970, 41, 184 